\title{
Colon Targeting Using pH Sensitive Materials
}

\author{
Ashish Jain* \\ Department of Pharmaceutical Sciences, India
}

Submission: December 13, 2017; Published: February 02, 2018

*Corresponding author: Ashish Jain, Department of Pharmaceutical Sciences, Dr. Hari Singh Gour Vishwavidyalaya, Sagar, Mandhya Pradhesh - 470 003, India, Tel: +91 9407551498, E-mail: ashishsemail@rediffmail.com

\begin{abstract}
The oral route is the preferred route for drug delivery, among oral delivery Intestine and colon drug delivery have been used for molecules aimed at local treatment of colonic diseases such as Colon Cancer, Polyp, Colorectal, Crohn's Disease, Inflammatory Bowel Disease (IBD), Ulcerative Colitis (UC) etc. and for delivery of molecules susceptible to enzymatic degradation such as peptides. There are various methods have been reported for colon targeting, among them use of $\mathrm{pH}$ sensitive polymers for coating and formulation of drug delivery system is most beneficial. The formulations of $\mathrm{pH}$ sensitive nanoparticles, hydrogel, microspheres, Polymeric Micelles are commonly reported for colon targeting. This review focuses on advancements of $\mathrm{pH}$ sensitive drug delivery system for colon targeting.
\end{abstract}

Keywords: Colon delivery; pH sensitive polymers; Nanoparticles; Hydrogel; Microspheres; Eudragit

\section{Introduction}

To supply a therapeutic amount of drug to a target site in a body is the major goal of any conventional or novel drug delivery system. Targeted drug delivery shows effective and selective localization of drug into the target site at therapeutic concentrations with limited access to non-target sites. A targeted drug delivery system is also preferred in drugs having instability, low solubility and short biological life. The colon specific drug delivery system should be capable of protecting the drug till itgets released to the colon i.e. drug release and absorption should not occur in the stomach and the small intestine, Thecolonissupposedtobeasuitableabsorption sitefordrugsbecauseoflack of digestive enzymes, relatively proteolytic activity of colon mucosa is much less in compare to the small intestine which leads to greater systemic bioavailability, and finally a long residence time up to 24 hour [1].

The absorptive capacity of the colon is much less as compared to small intestine because of mucosal surface of colon resembles that of the small intestine at birth but changes with age causing the loss of villi leaving a flat mucosa with deep crypt cells. Generally colon specific delivery of drugs is of interest for the treatment of colonic diseases, so as to maximize the effectiveness of these drugs.

\section{Approaches for targeting drugs into the colon}

Colonic targeting is advantageous in treating diseases of colon i.e. Colon Cancer, Polyp, Colorectal, Crohn's Disease,
Inflammatory Bowel Disease (IBD), Ulcerative Colitis (UC) etc., oral delivery of proteins and peptides where a delay in systemic absorption is therapeutically desirable (nocturnal asthma, arthritis).

Numerous invention approaches have been discovered to develop colon-targeted drug delivery systems. The difference in the $\mathrm{pH}$ along the GI tract is one of the approaches to achieve colon targeting. pH of different GI parts is given in Table 1. There are few methods have been developed for colon targeting i.e. utilization of Bacterial Enzymes, Time-Dependent Delivery System, pH- Triggered Delivery Systems.

Table 1: Characteristic of gastrointestinal tract. Intestinal diameter of Large intestinal $-6 \mathrm{~cm}$.

\begin{tabular}{|c|c|c|c|}
\hline S.No. & $\begin{array}{c}\text { Region Of } \\
\text { Gastrointestinal Tract }\end{array}$ & Length $\mathbf{( C m )}$ & Ph \\
\hline 1 & Cecum & $6-7$ & 5.5 \\
\hline 2 & Ascending Colon & 20 & $5.5-7$ \\
\hline 3 & Transverse colon & 45 & $5.5-7$ \\
\hline 4 & Descending colon & 30 & $5.5-7$ \\
\hline 5 & Rectum & 12 & 7 \\
\hline 6 & Anal canal & 3 & - \\
\hline
\end{tabular}

\section{pH- triggered delivery systems}

Radio telemetry shows the highest $\mathrm{pH}$ levels $7.5 \pm 0.5$ in the terminal ileum. On entry into the colon, the $\mathrm{pH}$ drops to $6.4 \pm 06$ 
and in the left colon $7.0 \pm 0.7$ [2]. So the polymer has $\mathrm{pH}$ specific solubility at equivalent $\mathrm{pH}$ is beneficial for colon targeting. However, a $\mathrm{pH}$ dependent polymer can shield a formulation in the stomach, and proximal small intestine, it may start to dissolve in the lower small intestine.

Enteric coatings are widely used in the pharmaceutical industry and have been experimented extensively in attempts to target colon. The $\mathrm{pH}$ sensitive materials can be used to encapsulate drug. These can be engineered to remain stable at low $\mathrm{pH}$, like those found in the stomach, and then release drugs at the higher $\mathrm{pH}$ of the intestine. Typically the polymers are carboxylated and interact (swell) very little with water at low $\mathrm{pH}$, whilst at high $\mathrm{pH}$ the polymers ionize causing swelling, or dissolving of the polymer. Coatings can therefore be designed to remain intact in the acidic environment of the stomach (protecting either the drug from this environment of the stomach), but to dissolve in the more alkaline environment found at intestine/colon [3].

The primary group of polymers used for the preparation of colon targeted dosage forms has been the Eudragits (registered trademark of Rohm Pharma Darmastadt, Germany), more precisely Eudragits L and S which are anionic polymers that are water resistant at low $\mathrm{pH}$. The ratio of the carboxyl to ester groups is almost 1:1 in Eudragit L 100 and 1:2 in Eudragit S100. These polymers form salts and dissolve at more than $\mathrm{pH}$ 7. Respectively Eudragit L 100 and S100 are copolymers of methacrylic acid and methyl methacrylate. The ratio of the carboxyl to ester groups is approximately 1:1 in Eudragit L 100-55, a copolymer of methacrylic acid and ethyl acrylate, which dissolves more than $\mathrm{pH}$ 5.5. This type of polymer disperses in water to form latex and avoids the use of organic solvents in the coating process. Eudragit L 30D-55 is a ready to use aqueous dispersion of Eudragit L10055 Eudragits L100, S100 and L100-55 are listed in the USP/NF 23 as methacrylic acid copolymer A, B and C respectively.

Thermocoat L 30 D55 is another methacrylic acid copolymer type $\mathrm{C}$ that is an aqueous dispersion of solid polymer. It is another $\mathrm{pH}$ dependent polymer which is dissolved in intestine to colon region, so these type of polymer were used to formulate enteric dosage form for intestinal and colon region [4]. DanBiloSyst has developed a simple-to manufacture colon targeting system (TARGIT) that is based on injection molded starch capsules coated with a mixture of Eudragit L and S. The composition and thickness of the coating of capsule is responsible for disintegration in the colon.

The use of carbopol is also a approach for colon targeting. The drug can be mixed with carbopol and granulated the tablets formed is coated with a semi-permeable membrane which allows water to enter. At around neutral $\mathrm{pH}$ (colon $\mathrm{pH}$ ) carbopol starts swelling, thus rupturing the coating and releasing the drug.

Several formulation approaches have been explored in the development colon- targeted drug delivery systems which involve the use of formulation components that interact with one or more aspects of gastrointestinal (GI) physiology, such as the difference in the $\mathrm{pH}$ along the GI tract, the presence of colonic microflora, and enzymes, to achieve colon targeting. There are various types of novel drug delivery systems has been developed to target the colon i.e. nanoparticles, microparticles, hydrogels etc.

\section{Nanoparticles/ Microparticles/microspheres}

Nanoparticles and microparticles are solid particles involving macromolecular materials in which the drug or biologically active material is entrapped, dissolved, or encapsulated or the active material is absorbed by or attached to their surface [5].

Mishra [6] prepared $\mathrm{pH}$ sensitive nanoparticles for colon targeted drug delivery system of Metoprolol succinate by Eudragit-P4135F and HPMC-AS and found that Eudragit-P4135F and HPMC-AS can be used to prepared nanoparticles which have enteric coating properties to target the drug to the colon. Targeted delivery to the colon is being explored for local colonic pathologies as well as for systemic delivery of drugs like proteins and peptides, which are degraded and/or poorly absorbed in stomach and small intestine but may be better absorbed from the more benign environment of the colon. ThermocoatL30D55 a $\mathrm{pH}$ sensitive polymer hasbeen reportedtoimprovethe shelf life of pellets, granules and powders and to improve selfprotection against environmental effects like humidity, light, temperature, which was used to develop $\mathrm{pH}$ dependent Tulsion ${ }^{\circledR}$ microspheres for colon specific delivery using quasi emulsion spherical crystallization technique and a combined mechanism of release, which combines specific biodegradability of polymer and $\mathrm{pH}$ dependent release from the coated microspheres was proposed [4].

Shi et al. [7] studied about pH-sensitive and colon-targeting P(LE-IA-MEG) hydrogel microspheres used for ulcerative colitis therapy and demonstrated desirable colon targeting property from The pharmacokinetic studies. Agrawal et al. [8] Formulated separately colon targeted $\mathrm{pH}$ pendent microspheres using $\mathrm{pH}$ sensitive polymer Eudragit L100, S100 of capecitabine for colorectal cancer to reduce dosing frequency and improve patient compliance.

\section{Hydrogels}

Hydrogels are cross-linked, hydrophilic polymeric networks that are able to absorb huge amounts of water within their 3-dimensional structures [9] It can be made to undergo sol-gel transition by various stimuli such as temperature and $\mathrm{pH}$ [5].

$\mathrm{pH}$-sensitive hydrogels are found suitable candidates for oral delivery of therapeutic peptides, proteins, and drugs, due to their ability to respond to environmental $\mathrm{pH}$ changes in earlier studies. Mahkam 2006 prepared pH-sensitive glycopolymers for Colon-Specific Drug Delivery by free-radical polymerization of methacrylic acid and 6-acryloyl-glucose-1, 2, 3, 4-tetraacetate, using 1, 6-hexandiol diacrylate and 1, 6-hexandiol propoxylate diacrylate as cross-linking agents. 


\section{Polymeric micelles}

Polymeric micelles are nano-sized carriers having a spherical inner core and an outer shell prepared by selfassembly of amphiphilic copolymers in an aqueous solution [10]. The inhibition effect of Curcumin on tumor formation by affecting the initiation and progression stage of carcinogenesis of colorectal cancer has been investigated using Curcumin Containing Chitosan-Based pH-Sensitive Polymeric Micelles for Colon-Targeted Drug Delivery [11].

\section{Conclusion}

Both local and systemic delivery of drugs can take place at the site of colon. Among them local delivery allows topical treatment of various colonic diseases. As the $\mathrm{pH}$ varies at different parts of GIT $\mathrm{pH}$ sensitive polymers are insoluble at lower $\mathrm{pH} \&$ get solubilized as the $\mathrm{pH}$ increases i.e., colon. Colon targeting makes the treatment effective by reducing the systemic side effects. Colon targeting also provide significant benefits to the patients in terms of safety, efficacy, and patient compliance. With combined methods, nanotechnology gives the impression to be a future research area for colon targeting.

\section{References}

1. Kumar A, Aggarwal G, HariKumar SL (2015) Colon Specific Drug Delivery by pH Sensitive Polymers \& Pulsatile Drug Delivery System. Indo Global Journal of Pharmaceutical Sciences 5(1): 6-11.

2. Evans DF, Pye G, Bramley R, Clark AG, Dyson TJ, et al. (1988) Measurement of gastrointestinal $\mathrm{pH}$ profiles in normal ambulant human subjects. Gut 29(8): 1035-1041.
3. Mizumori M, Ham M, Guth PH, li Engel E, Kaunitz J D, et al. (2009) Intestinal alkaline phosphatase regulates protective surface microclimate pH in rat duodenum. J Physiol 587(pt 14): 3651-3663.

4. Jain A, Jain A, Jain A, Jain A (2016) Quasi emulsion spherical crystallization technique based environmentally responsive Tulsion ${ }^{\circledR}$ ( $\mathrm{pH}$ dependent) microspheres for colon specific delivery. Journal of applied biomedicine, 14(2):147-155.

5. Jain A, Jain A, Gulbake A, Shilpi S, Hurkat P, et al. (2013) Peptide and protein delivery using nanocarriers. Critical reviews in therapeutic drug delivery system. 30(4): 293-329.

6. Mishra S (2013) Formulation and evaluation of $\mathrm{pH}$ sensitive nanoparticles for colon targeted drug delivery system, 3rd International Conference and Exhibition on Pharmaceutics \& Novel Drug Delivery Systems Hilton Chicago/Northbrook, USA.

7. Shi X, Yan Y, Wang P, Sun Y, Zhang D, et al. (2017)In vitro and in vivo study of $\mathrm{pH}$-sensitive and colon-targeting $\mathrm{P}$ (LE-IA- MEG) hydrogelmicrospheres used for ulcerative colitis therapy. Eur J Pharm Biopharm 122: 70-77.

8. Agrawal D, Ranawat MS, Chauhan CS, Kamble R (2013) Formulation and charecterisation of colon targeted $\mathrm{pH}$ dependent microspheres of capecitabine for colorectal cancer. Journal of drug delivery \& Therapeutics 3(6): 215-222.

9. Moriyama K, Yui N (1996) Regulated insulin release from biodegradabledextran hydrogels containing poly (ethylene glycol). Journal of Control Release 42(3): 237-248.

10. Yokoyama M (2011) Clinical application of polymeric micelle carrier systems in chemotherapy and image diagnosis of solid tumors. Journal of Experimental Clinical Medicine 3(4): 151-158.

11. Woraphatphadung T, Sajomsang W, Rojanarata T, Ngawhirunpat T, Tonglairoum P, et al. (2017) Development of chitosan-based phsensitive polymeric micelles containing curcumin for colon-targeted drug delivery. AAPS PharmSciTech.
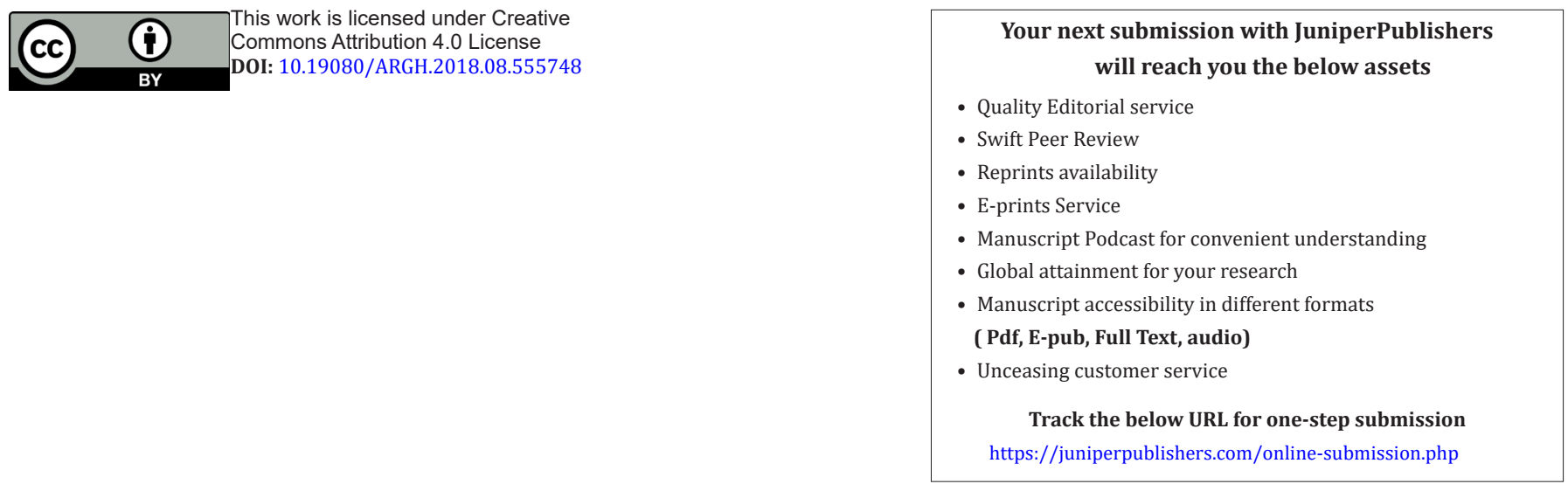